\section{CHEMICAL LECTURE EXPERIMENTS}

SEVERAL interesting and instructive experiments have been described of late in the chemical journals: we propose to give a short account of the more important.

\section{[I. - Physico-CHEMICAL EXPERIMENTS}

A. Mixing of Gases by Diffusion.-That gases do not mix very rapidly by diffusion alone, may be illustrated by placing a strip of white paper moistened with lead acetate solution inside a tall glass stoppered cylinder, so that when the cylinder is inverted the paper extends from the bottom (which now forms the uppermost end) not more than one-third of the total length of the cylinder. A little sulphuretted hydrogen water is placed in the hollow stopper of the cylinder, and the stopper is inserted loosely into its place. After ten to fifteen minutes the production of brown lead sulphide on the white paper shows that the sulphuretted hydrogen gas has risen two-thirds of the height of the cylinder. Paper moistened with starch and potassium iodide, and chlorine water, may respectively replace the lead acetate paper and the sulphuretted hydrogen water (C. von Than, Berichte, xii. I414).

B. Liquefaction of Gases by Increasing Pressure or Lowering Temperature.-Ethylic chloride, which boils at $\mathbf{1} 2^{\circ}$, is easily liquefied. A Hofmann's lecture eudiometer, with one limb about $100 \mathrm{~cm}$. and the other $50 \mathrm{~cm}$ in length, serves as apparatus. The eudiometer is filled with mercury ; ethylic chloride gas is led into the shorter limb through the upper stopcock, while the mercury flows out by the other stopcock; when the smaller limb is partly filled with gas, the mercury is adjusted to the same level in both limbs, the gas is liquefied by pouring ether over the shorter limb, and any air which has entered with the gas is allowed to escape by opening the upper stopcock for a moment. The liquid ethylic chloride is gasified by running out as much as possible of the mercury in the larger limb, and so reducing the pressure. If the temperature is lowered-by pouring ether on to the outside of the shorter limb-or if the pressure is increased-by pouring mercury into the longer limb, equal to an extra half atmosphere of pressure-the ethylic chloride becomes liquid (Hofmann, Berichte, xii. I I24).

C. Absorption of Heat Accompanying Change from Liquid to Gaseous Form.-A test tube, partly filled with water, is placed in a small glass cylinder containing ether sufficient to completely cover that part of the tube in which there is water. A brisk stream of dry air is driven through the ether, which rapidly evaporates; in a few minutes the water in the tube is completely frozen (Hofmann, Berichte, xii. I 125 ).

D. Thermal Changes Attending Solution of Salts in Water.-A small flask of about Ioo cc. capacity is fitted with a cork carrying a glass tube, 3-4 mm. diameter, bent twice at right angles; the larger limb of the tube is about $70 \mathrm{~cm}$. in length, and passes through a cork nearly to the bottom of a wide-mouthed bottle, of about 40 cc. capacity, containing coloured water. A straight piece of similar tubing of about the same length passes through a second hole in the cork, and also reaches nearly to the bottom of the wide-mouthed bottle. The salt under examination is placed in the flask, water is added, and the cork is inserted. If heat is evolved during solution, the coloured water rises in the straight glass tube, which is open at the upper end; if heat is absorbed during solution, the water rises in the tube connected with the small flask (Rosenfeld, Berichte, xiii. I475).

\section{II.-Experiments Illustrative of Chemical ACTION IN GENERAL}

A. Conservation of Mass.-Two small glass tubes, about I $5 \mathrm{~cm}$. long by $2 \mathrm{~cm}$. wide; are sealed and rounded off at one end and drawn out at the other to tubes about $3 \mathrm{~mm}$. diameter. About two centigrams of freshly heated char- coal is dropped into one tube, the air is replaced by dry oxygen, which is led in by a capillary tube passing through the narrow opening, and the tube is sealed. The other tube is also sealed at a point such that the weights of the two tubes are equal. The tubes are placed on the opposite pans of a balance, and the balance is shown to be in equilibrium: that tube which contains charcoal is heated by a small gas-flame, the charcoal burns brilliantly, and by carefully shaking the tube is all, or almost all, consumed. When the tube is cold it is replaced on the balance pan, on releasing the beam it is found that no change has occurred in the mass of matter in the tube, although the form of the matter has undergone most marked change. Sulphur, or a very small quantity of gun-cotton, may be employed in place of charcoal in this experiment (C. von Than, Berichte, xii. I4I3).

B. The Individual Substances taking part in a Chemical Chainge Gain or Lose Weight.-To demonstrate that a substance increases in weight during oxidation, \&c., or loses weight during reduction, \&c., a piece of copperwire, about $10 \mathrm{~cm}$. long by $\mathrm{I} \mathrm{mm}$. thick, is fused into the upper end of a glass hydrometer: the wire carries a little glass cup (the bottom part of a test tube serves admirably) on its upper end, on which lies a piece of platinum foil. The hydrometer is placed in water contained in a cylinder. Such a quantity of finely divided iron as suffices to sink the hydrometer, so that the wire is just wetted, is placed on the platinum foil; the foil is removed, heated till the iron is oxidised, allowed to cool, and replaced on its support: the hydrometer sinks considerably in the water. To illustrate loss of weight on reduction, a little cylinder of copper oxide, made by mixing the substance with gum and drying, may be employed. Before the reduction is commenced, nearly the whole of the wire supporting the platinum foil ought to be immersed in the water (Rosenfeld, Berichte, xiv. 2 IO2).

C. Influence of Mass, Time, etc., on a Chemical .Change. -The influence of time, temperature, and mass, as also the meaning of the phrase reverse action, may be qualitatively illustrated as follows:- Three beakers are arranged on white surfaces and with white backgrounds; in beaker (I) is placed about 100 cc. of cold water, in (2) the same quantity of water at $90^{\circ}-100^{\circ}$, and in (3) about $500 \mathrm{cc}$. of cold water. A few drops of a solution of bismuth iodide in concentrated hydriodic acid is poured into each beaker; brown bismuth iodide is precipitated in the first beaker, red bismuth oxyiodide in the second, and the same salt, but in smaller quantity, in the third. On standing for a little time, the brown iodide is slowly changed into red oxyiodide; but on adding a little concentrated hydriodic acid, the reverse change-viz. from oxyiodide to iodide--takes place (Muir, Chem. Soc. Journ. Trans., $1882,6)$.

The influence of mass and time on a chemical change may be quantitatively exhibited by arranging a series of similar glass cylinders filled with water, and inverted in glass basins : a stoppered retort of about 100 cc. capacity is supported close to each cylinder. The retorts are carefully cleaned, and $50 \mathrm{cc}$. of pure sulphuric acid, regularly diminishing in concentration by a fixed amount, is placed in each. Sheet zinc is cut into squares of equal sizes, which are rolled into slit cylinders (by bending round a glass rod), cleansed in soda solution, then washed, immersed in strong sulphuric acid, again rapidly washed in a stream of water, and dropped into the retorts, which are then stoppered. The hydrogen which is evolved is collected as long as the areas of the zinc remain visibly constant. The upper surfaces of the water in the cylinders exhibit, in the form of a curve, the influence of the mass of sulphuric acid on the change under consideration. As the evolution of hydrogen may be stopped at any moment by withdrawing the stopper of a retort, the experiment may be arranged to show the influence of time on the change (Mills, Chem. Soc. Journ. Trans., I880, 454). 


\section{III.-EXPERIMENTS Illustrative OF Combustion PHENOMENA}

A. Burning Oxygen in Sulphur Vapour.-A twonecked balloon is fitted with corks, each carrying a tube, one of which passes towards the bottom of the balloon, and has its tip slightly bent upwards, the other, beginning flush with the inner surface of the cork, passes downwards into a cylinder containing water. The first of these tubes communicates, by means of a long piece of caoutchouc tubing, with a supply of dry oxygen. About 40 to 50 grams of dry sulphur are placed in the balloon, and heated till the vessel is quite filled with reddish vapours, the oxygen delivery tube being meanwhile withdrawn. Oxygen is allowed to flow from the delivery tube in a stream sufficiently rapid to cause a glowing chip of wood held 2 to 3 millims. from the end of the tube to burst into flame; a small piece of charcoal is attached by platinum wire to the tip of the oxygen delivery tube ; the charcoal is ignited, and the cork carrying the tube which delivers oxygen is inserted into the neck of the balloon. The oxygen is soon seen burning in the vapour of sulphur which fills the vessel; the product of combustion, viz. sulphur dioxide, is led by the second tube into the water in the cylinder, the presence of sulphurous acid in which is easily exhibited (C. von Tham, loc. cit.).

B. Burning Sulphuretted Hydrogen in Vapour of Nitric Acid. -6o to 80 c.c. of concentrated nitric acid (sp. gr. I.53) are placed in a flask of 500 c.c. capacity. A rapid stream of sulphuretted hydrogen is passed, through water, into the acid, whereupon red fumes are copiously produced. The delivery tube is slowly raised from the surface of the acid towards the neck of the flask; at a certain distance from the acid the sulphuretted hydrogen takes fire and burns with a blue flame; the upper part of the flask becomes filled with white fumes of sulpuric acid, the lower part with red fumes of oxides of nitrogen, little or no sulphur separating (Kessel, Berichte, xii. 2305).

C. Burning Ammonia in Oxygen.-A wide-mouthed flask is fitted with a cork, which carries a tube passing nearly to the bottom of the flask, and also a large straight drying tube, which contains solid caustic soda and is closed at its upper end by a cork carrying a little piece of tubing drawn out to an opening about $2 \mathrm{~mm}$. in diameter. A quantity of strong ammonia liquor is placed in the flask and heated nearly to boiling, the lamp is withdrawn, and the cork with its tube inserted. A stream of oxygen is passed into the hot liquor, and the dry ammonia, mixed with oxygen, is ignited as it issues from the caustic soda tube. As the amount of ammonia diminishes, the flame becomes smaller, but very hot; a piece of platinum wire may be melted, or a lime cylinder may be caused to give out much light, by holding it just above the central zone of the flame (Rosenfeld, Berichte, xiv. 2104 , and xv. 169.)

D. To show that Water is produced by Burning Hydrogen in Oxygen.- A small platinum flask (as is figured in Roscoe and Schorlemmer's "Chemistry," I., p. 339) is rurnished with a good cork carrying two tubes of ordinary pipe-clay, which reach towards the bottom of the flask: one of these tubes communicates by caoutchouc tubing with a supply of dry hydrogen, the otber with a supply of dry oxygen. The exit-tube of the flask is attached to a piece of glass tubing which connects with a glass worm condenser, underneath which a beaker is placed. Dry hydrogen is passed into the flask until the air is completely replaced from the entire apparatus : while this is being done, the caoutchouc tubing which connects the clay tube with the oxygen supply is securely clamped just above its junction with the clay pipe, to prevent hydrogen from diffusing backwards into the oxygen tubes, and so forming an explosive mixture. When the air is all driven out of the apparatus, the platinum flask is heated to redness, dry oxygen is passed into it, and the lamp is withdrawn. By properly regulating the streams of oxygen and hydrogen, so much heat is produced that the flask becomes nearly white hot; water is quickly formed and trickles, and after a little, flows in a continuous stream through the glass worm into the beaker beneath (Hofmann, Berichte, xii. I 122 ).

E. Unburning of $W$ ater-gas by Iron and by Magnesium.-3-4 grams very finely divided iron (Ferrum alcoholisatum) are placed in a small piece of hard glass tubing about $12 \mathrm{~cm}$. long and $\mathrm{I} 4 \mathrm{~mm}$. diameter. One end of this tube is connected with a flask containing hot water, the other with an ordinary gas exit-tube and small pneumatic trough. The iron is heated, the water brought to, and just maintained at the boiling-point, and the end of the delivery-tube is plunged under the water in the trough. Hydrogen is obtained in a rapid stream. As thus arranged the decomposition of water-gas by iron is readily shown without the use of a furnace or porcelain tube.

A similar apparatus serves to show the decomposition of water-gas by magnesium; a piece of magnesium-ribbon about $60 \mathrm{~cm}$. long is folded on itself so as to form a bundle about $\mathrm{I} \mathrm{cm}$. in length, which is placed in the glass tube; the water is kept nearly boiling; the magnesium is heated until it begins to melt and burn at the edges, at this moment the water is rapidly boiled (and the exit-tube is plunged under the water in the trough), when the magnesium is found to burn vividly in the steam and hydrogen to be evolved in quantity (Rosenfeld, Berichte, I5, 160.

M. M. P. M

\section{NOTES}

WE are glad to learn that one of the evening (Friday, August 25) discourses at the Southampton meeting of the British Association will be given by Sir William Thonson, and that the subject will be "Tides." Prof. Moseley's discourse on "Pelagic Life" will be given on Monday evening, August 28.

THE honour of Companion of the Order of St. Michael and St. George has been conferred upon Mr. W. T. Thiselton Dyer, F.R.S., Assistant Director of the Royal Botanical Gardens, Kew, for services rendered to Colonial Governments.

THE FRENCH Minister of Public Instruction has again appointed a Commission to direct the deep sea exploration of the Atlantic in the Travailleur in July and August next; the investigation will include the ocean bed along the coasts of Spain, Portugal, and Morocco. The members of the Commission are MM. A. Milne-Edwards, L. Vaillant, E. Perrier, Marion, Folin, and P. Pischer.

A Florence correspondent writes:-“On Sunday, May 2I, the students and professors of the Faculties of Science and Medicine of Florence assembled to celebrate the memory of Charles Darwin. The large aula of the "Istituto" was crowded with auditors, and many had to be content with standing-room in the corridor outside. An address was read by the representative of the students, and an eloquent study of the genius and character of the great man of science by Prof. Mantegazza. I was struck by the note of religious solemnity that marked the proceedings." Similar testimonies of the high veneration in which the name of Darwin is held abroad come to us from other parts of Italy, as well as France, Germany, Norway, and Russia.

WE lately noticed the death of Mr. T. Donovan, lecturer on physiology and other scientific subjects at the Working Men's College and at the Birkbeck Instifution. We learn that he has left a widow and two children, whose position has excited the sympathy of some of those who know the value of the work he did, and that a committee has been formed to collect a fund for their assistance. Mr. R. B. Litchfield, Bursar of the Working Men's College, whose address is 4, Bryanston Street, Portman Square, W., is Treasurer of the Fund. 